\title{
Effects of electron irradiation on structure and bonding of $\mathrm{SF}_{6}$ on $\mathrm{Ru}(0001)$
}

\author{
N.S. Faradzhev, D.O. Kusmierek, B.V. Yakshinskiy, and T.E. Madey \\ Department of Physics and Astronomy and Laboratory for Surface Modification, Rutgers University \\ 136 Frelinghuysen Rd., Piscataway, NJ 08854-8019, USA \\ E-mail: madey@physics.rutgers.edu
}

Received July 22, 2002, revised August 14, 2002

\begin{abstract}
Electron stimulated desorption ion angular distribution (ESDIAD) and temperature programmed desorption (TPD) techniques have been employed to study radiation-induced decomposition of fractional monolayer $\mathrm{SF}_{6}$ films physisorbed on $\mathrm{Ru}(0001)$ at $25 \mathrm{~K}$. Our focus is on the origin of $\mathrm{F}^{+}$and $\mathrm{F}^{-}$ions, which dominate ESD from fractional monolayers. $\mathrm{F}^{-}$ions escape only in off-normal directions and originate from undissociated molecules. The origins of $\mathrm{F}^{+}$ions are more complicated. The $\mathrm{F}^{+}$ions from electron stimulated desorption of molecularly adsorbed $\mathrm{SF}_{6}$ desorb in off-normal directions, in symmetric ESDIAD patterns. Electron beam exposure leads to formation of $\mathrm{SF}_{x}(x=0-5)$ fragments, which become the source of positive ions in normal and off-normal directions. Electron exposure $>10^{16} \mathrm{~cm}^{-2}$ results in decomposition of the entire adsorbed $\mathrm{SF}_{6}$ layer.
\end{abstract}

PACS: 79.20.La

\section{Introduction}

As part of a program to study radiation-induced processes in adsorbed fluorine and chlorine-containing molecules [1-4], we are examining electron stimulated desorption (ESD) of $\mathrm{SF}_{6}$ adsorbed on a single crystal metal surface. This study has several components, including: 1) the study of the structure and reactivity of $\mathrm{SF}_{6}$ on a clean $\mathrm{Ru}(0001)$ [5] surface; 2 ) the influence of coadsorbed atoms and molecules in ESD of $\mathrm{SF}_{6}$ (including a search for enhancement of the $\mathrm{F}^{-}$ ESD signal [1-3]); 3) electron beam damage processes in the adsorbed layer. The present paper focuses on the latter: the effects of electron bombardment on the structure and bonding of $\mathrm{SF}_{6}$, as revealed by changes in $\mathrm{F}^{+}$and $\mathrm{F}^{-}$ESD yields and angular distributions.

Sulfur hexafluoride, $\mathrm{SF}_{6}$, is a highly symmetric, inorganic, chemically inert, man-made molecule. The sulfur atom resides at the center of a regular octahedron, whose corners are occupied by the six fluorine atoms. $\mathrm{SF}_{6}$ has a positive electron affinity, whose presently accepted value is $\sim 1.06 \pm 0.06 \mathrm{eV}$ [6]. Based upon studies of low-energy electron interactions with gaseous $\mathrm{SF}_{6}$, it is known that gaseous $\mathrm{SF}_{6}$ attaches thermal and near thermal electrons with a very large cross-section to become $\mathrm{SF}_{6}^{-}$. This ability to capture thermal electrons makes $\mathrm{SF}_{6}$ popular for technical applications as an electron scavenger in high voltage electrical devices [7]. $\mathrm{SF}_{6}$ is also used as a dry-etching gas in plasma processing [8] and is known to be a greenhouse gas.

Previous experiments with $\mathrm{SF}_{6}$ adsorbed on $\mathrm{Ru}(0001)$ [9] and $\mathrm{Ni}(111)$ [10] indicate that $\mathrm{SF}_{6}$ is physisorbed on the metal surface. Based upon the structure of $\mathrm{SF}_{6}$ and of $\mathrm{Ru}(0001)$, it was argued that the molecule should be oriented so that one set of three $\mathrm{F}$ atoms is in contact with the substrate and the other set of three $\mathrm{F}$ atoms lies in a plane parallel to the surface facing the vacuum. Since the threefold symmetry of $\mathrm{SF}_{6}$ coincides to such a large degree with the symmetry of the (0001) plane of $h c p$ Ru, preferred adsorption sites and some degree of ordering of the molecule are highly probable.

ESD of adsorbed molecules implies desorption of neutral fragments (atoms and molecules) as well as both positive and negative ions. Electron stimulated desorption ion angular distribution (ESDIAD) is a very useful technique for determining the bonding structure of molecules adsorbed on single-crystal surfaces [11], since the trajectory of the desorbing particle is determined mainly by the orientation of the 
bond that is broken. ESDIAD also has a great utility for providing insights into structure and dynamics of decomposition of adsorbed molecules under electron bombardment [12]: distinct electron-induced changes in the ESDIAD patterns and intensities of specific ions can be monitored and analyzed. In this paper we concentrate on both $\mathrm{F}^{+}$and $\mathrm{F}^{-}$ions produced by ESD of a fractional $\mathrm{SF}_{6}$ layer (0.25 ML) adsorbed on a $\mathrm{Ru}(0001)$ substrate (because of the high electron affinity of the $\mathrm{F}$ atom, we expect a strong $\mathrm{F}^{-}$signal in ESD).

In the gas-phase, the low-energy dissociative electron attachment (DEA) resonance that leads to $\mathrm{F}^{-}$ formation is due to the reaction

$$
e^{-}(2.7 \mathrm{eV})+\mathrm{SF}_{6} \rightarrow \mathrm{F}^{-}+\mathrm{SF}_{5}
$$

The thermodynamic threshold is $0.65 \mathrm{eV}$ [7]. In the condensed-phase, the $\mathrm{F}^{-}$signal is dominated by two resonant features, with maxima at $5.8 \mathrm{eV}$ and $\sim 11 \mathrm{eV}$. A very weak signal is also detected between 1 and $3 \mathrm{eV}$ [7].

In the gas-phase, electron-induced dissociation of $\mathrm{SF}_{6}$ leading to the formation of positive ions becomes significant above $\sim 16 \mathrm{eV}$, producing $\mathrm{SF}_{x}{ }^{+}(x=1,3$, $4,5)$ and $\mathrm{F}^{+}$[6]. Measurements of electron impact dissociative ionization of gaseous $\mathrm{SF}_{6}$ give the threshold energy for $\mathrm{F}^{+}$formation somewhere in the range of 30-50 eV [13,14], very different from $\mathrm{F}^{-}$. The comparison of ESDIAD images for $\mathrm{F}^{+}$and $\mathrm{F}^{-}$should provide insights into the mechanisms of ion formation.

In order to understand better the behavior of adsorbed $\mathrm{SF}_{6}$ on $\mathrm{Ru}(0001)$ under electron irradiation, we utilize several surface-sensitive techniques, mainly temperature programmed desorption (TPD) and ESDIAD. The major findings of this work include establishing the dissociation dynamics of fractional monolayers of $\mathrm{SF}_{6}$ adsorbed on $\mathrm{Ru}(0001)$, insights into the origins of $\mathrm{F}^{+}$and $\mathrm{F}^{-}$ions, and the difference in sensitivity to electron exposure of fractional monolayer and multilayer coverages of $\mathrm{SF}_{6}$. We find that the $\mathrm{F}^{-}$ions originate primarily from undissociated $\mathrm{SF}_{6}$ molecular adsorbates, while the $\mathrm{F}^{+}$ions have a high yield from both molecular $\mathrm{SF}_{6}$ and adsorbed dissociation fragments.

Section 2 outlines the experimental procedures, sec. 3 focuses on the results obtained, and sec. 4 provides a discussion of the results presented and offers possible explanations.

\section{Experimental procedures}

Experiments have been carried out in an ultrahigh vacuum (UHV) chamber equipped with apparatus for Auger electron spectroscopy (AES), low energy electron diffraction (LEED) and temperature prog- rammed desorption (TPD). The chamber houses two detectors for ESD experiments: a quadrupole mass spectrometer (QMS) and an electron stimulated desorption ion angular distribution detector. The chamber is ion-pumped, reaching a base pressure of $\sim 5 \cdot 10^{-11}$ torr after system bakeout.

The substrate is a $\mathrm{Ru}(0001)$ single crystal mounted on a copper sample holder connected to a manipulator and attached to a closed-cycle helium refrigerator, which cools the sample to $\sim 25 \mathrm{~K}$. The sample can be heated to $1600 \mathrm{~K}$ by electron bombardment of its backside. Substrate temperature is measured by a chromel-alumel thermocouple attached directly to the sample. The crystal surface is cleaned by sputtering using $1 \mathrm{keV} \mathrm{Ar}{ }^{+}$ions, heating in oxygen, followed by annealing in vacuum. The procedure ensures effective cleaning of the surface, which demonstrates a distinct $1 \times 1$ LEED pattern. The absence of contaminants is monitored by AES and work function measurements.

High purity $(99.95 \%)$ sulfur hexafluoride $\left(\mathrm{SF}_{6}\right.$ : «Matheson») is deposited onto the clean surface at $25 \mathrm{~K}$ via a directional capillary array gas doser. Gas purity is checked by QMS (residual-gas analysis mode) as it is introduced into the chamber. Coverages are determined by temperature-programmed desorption measurements. For TPD studies, the Ru sample is heated by radiation from a hot $\mathrm{W}$ filament approximately $\sim 1 \mathrm{~mm}$ from its backside. A negative bias is applied to the sample to prevent electron bombardment from either the heating filament or QMS filament, as the temperature is increased.

A Kimball Physics series electron gun, providing a focused beam of electrons in the energy range of $20-1000 \mathrm{eV}$, is the source of electron irradiation in the electron stimulated desorption experiments. The incidence angle of primary electrons is $55^{\circ}$ with respect to the sample normal.

ESD mass-spectra of positive ions are obtained using the QMS to detect ions produced upon electron bombardment of adsorbed $\mathrm{SF}_{6}$. In this mode of operation, ESD-mode, the ion-source filament of the QMS is turned off, and the electron gun is used to bombard the sample with a focused electron beam, $\sim 1 \mathrm{~mm}^{2}$ in area. Typically, the energy of the incident electrons is $200 \mathrm{eV}$ and the sample is held at $+20 \mathrm{~V}$.

The ESDIAD detector allows us to perform angle-resolved ESD studies of both negative and positive ions. Time-of-flight (TOF) mass separation of desorbing species is accomplished by pulsing the primary electron beam and gating a retarding grid with a repetition rate of $10 \mathrm{kHz}$ and duration of $200 \mathrm{~ns}$. Unless otherwise specified, angular distributions of desorbing $\mathrm{F}^{+}$have been measured for incident electron kinetic energies of $350 \mathrm{eV}$ ( $250 \mathrm{eV}$ electron gun energy 
and sample bias of $+100 \mathrm{eV}$ ). Measurements for $\mathrm{F}^{-}$ ions were made for incident electron energies of $250 \mathrm{eV}(350 \mathrm{eV}$ electron gun energy and sample bias of - $100 \mathrm{eV})$. The sample bias is applied in order to accelerate escaping ions and achieve a wider collection angle. The total electron beam exposure used to obtain the ESDIAD images is $\sim 10^{12}-10^{13} \mathrm{~cm}^{-2}$. The details of the experimental technique have been reported elsewhere [15-17].

All ESDIAD measurements reported in this paper are made with the sample cooled to $\sim 25 \mathrm{~K}$. Thermally induced changes in ESDIAD patterns were «frozen» after annealing by cooling to $\sim 25 \mathrm{~K}$, before measurements were made.

For experiments involving TPD associated with electron beam damage of the adsorbed layer, the sample is held at $+20 \mathrm{~V}$ potential and $90 \mathrm{eV}$ electrons from the QMS filament $(I \sim 1.5 \mu \mathrm{A}, E \sim 70 \mathrm{eV})$ bombard the sample. The QMS filament provides a defocused electron beam that allows for irradiation of the whole sample, in contrast to the electron gun with a focused electron beam that irradiates $\sim 1 \mathrm{~mm}^{2}$ of the target sample.

TPD measurements [5] indicate that the $\mathrm{SF}_{6}$ molecules are primarily physisorbed on the Ru substrate. We estimate a constant sticking probability $(\sim 1)$ for $\mathrm{SF}_{6}$ at $25 \mathrm{~K}$ [5]. Based on the packing density of the basal plane of ruthenium $\left(1.58 \cdot 10^{15}\right.$ atoms $\left./ \mathrm{cm}^{2}\right)$, and the molecular size of $\mathrm{SF}_{6}$, we identify the saturation coverage of $\mathrm{SF}_{6}$ in the first adsorbed layer as $\sim 0.33$ ML $\left(5.3 \cdot 10^{14}\right.$ molecules $\left./ \mathrm{cm}^{2}\right)$.

\section{Results}

\subsection{ESD mass-spectra}

Figure 1 shows typical ESD mass-spectra measured for positive ions at fractional monolayer (Fig. 1,a) and multilayer (Fig. 1,b) coverages of $\mathrm{SF}_{6}$ on $\mathrm{Ru}(0001)$. Data are obtained using the QMS (ESD-mode) with incident electron energies of $200 \mathrm{eV}$ and a sample bias of $+20 \mathrm{~V}$. Figure 1, $c$ shows the gas phase spectrum for comparison.

In the fractional monolayer regime, the condensed-phase spectrum (Fig. 1,a) exhibits a strong $\mathrm{F}^{+}$ion signal. The yield of other fragments is suppressed. Increasing the coverage leads to changes in desorption yields of positive ions. As the coverage grows (Fig. 1,b, $2.5 \mathrm{ML} \mathrm{SF}_{6}$ ), we detect a considerable increase in desorption of singly charged fragments: $\mathrm{S}^{+}$ and $\mathrm{SF}_{x}{ }^{+}$ions $(x=1, \ldots, 5) \cdot \mathrm{SF}_{6}{ }^{+}$species are not observed. Note the extremely low yield of $\mathrm{SF}_{4}^{+}$fragments, which are barely detected in the spectrum.

The gas-phase spectrum for positive ions shown in Fig. 1,c agrees with the NIST Chemistry WebBook

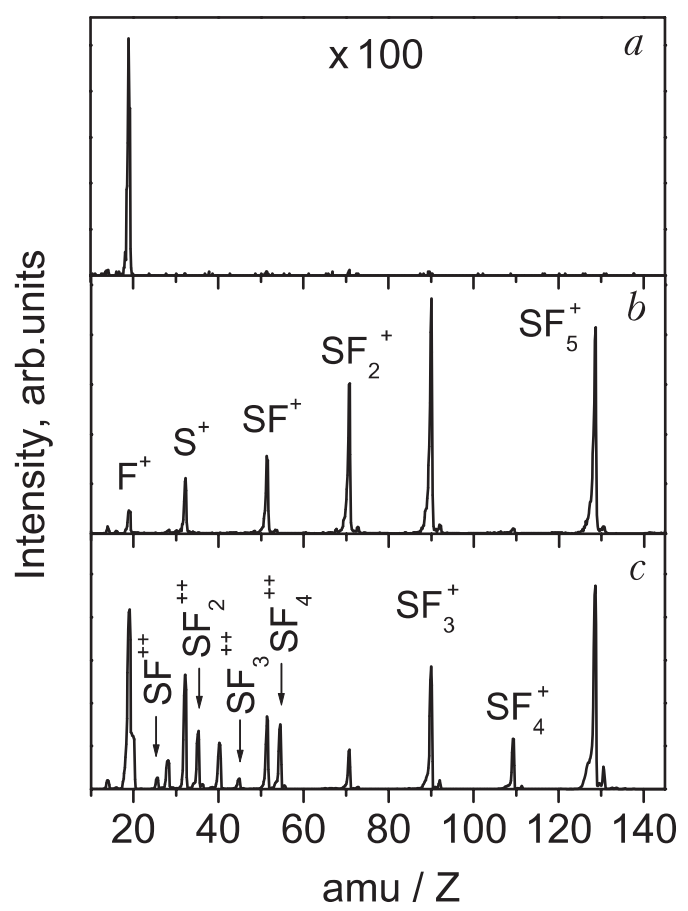

Fig. 1. Mass-spectra for ESD of positive ions from $\mathrm{SF}_{6}$ on $\mathrm{Ru}(0001)$ for coverages: $0.25 \mathrm{ML}(a)$ and $2.5 \mathrm{ML}(b)$. Sample bias is $+20 \mathrm{~V}$. Incident electron energy is $220 \mathrm{eV}$. Gas-phase spectrum for positive ions (equilibrium pressure of $\mathrm{SF}_{6}$ in chamber is $1 \times 10^{-7}$ Torr) $(c)$.

[18], except that we detect higher relative yields of $\mathrm{F}^{+}$ and $\mathrm{S}^{+}$ions, which may be due, in part, to the contribution of ESD from species adsorbed on parts of the QMS. In contrast to thick $\mathrm{SF}_{6}$ layers (Fig. $1, b$ ), the gas phase $\mathrm{SF}_{4}^{+}$signal (although smaller than the $\mathrm{SF}_{3}^{+}$ and $\mathrm{SF}_{5}^{+}$signals), is comparable to yields detected for the other ions. As for the multilayer $\mathrm{SF}_{6}$ film on $\mathrm{Ru}$ (Fig. 1,b), no $\mathrm{SF}_{6}^{+}$is detected in the gas-phase. It is believed that this ion is unstable both in its ground state and its excited electronic states [6].

The spectrum in Fig. 1, $c$ also reveals the presence of doubly charged fragments: $\mathrm{SF}_{x}^{++}(x=1, \ldots, 4)$. The intensities of these fragments are related to the intensities of the corresponding singly charged ions, and are dependent on $x$. For even values of $x(2,4)$, the observed intensities of singly- and doubly charged ions are approximately equal, whereas for odd values of $x$ $(1,3)$ the doubly ionized fragment signals are smaller by about one order of magnitude. This observation is consistent with the partial electron-impact ionization cross-sections reported elsewhere [6].

In spite of the fact that the cracking pattern of ESD for negative ions contains only a few fragments, we observe the same tendency [5] as for positive ions. For fractional monolayer coverages, the $\mathrm{F}^{-}$ion is the main fragment escaping from the surface. A small frac- 
tion of $\mathrm{F}_{2}^{-}$ions is also observed in accordance with previous ESD studies reported for other halogenated molecules on $\mathrm{Ru}(0001)$ [4,19]. Increasing deposition of $\mathrm{SF}_{6}$ leads to changes in the spectrum, mainly the emergence of the $\mathrm{SF}_{5}^{-}$ion. The yield of this ion gradually increases and eventually even surpasses the $\mathrm{F}_{2}^{-}$ signal.

A more comprehensive treatment of the ESD mass spectra will be presented elsewhere [20].

In general, one can conclude that for $\mathrm{SF}_{6}$ molecules in the first adsorbed molecular layer, which are in contact with the ruthenium surface, desorption of relatively massive $\mathrm{SF}_{x}$ ions under electron bombardment is suppressed; the ESD signals are dominated by $\mathrm{F}^{+}$ and $\mathrm{F}^{-}$. This may be attributed, in part, to higher reneutralization rates for more massive, slow-moving ions, whereas less massive, fast-moving fluorine ions can easily escape from the substrate [21].

\subsection{Structure and bonding of $\mathrm{SF}_{6}$; thermal effects}

Experiments performed using ESDIAD reveal that after deposition of fractional monolayer coverage (0.25 ML) of $\mathrm{SF}_{6}$, strong off-normal emission of both $\mathrm{F}^{+}$and $\mathrm{F}^{-}$ions are observed. Typical «halo» patterns for $\mathrm{F}^{+}$and $\mathrm{F}^{-}$ions are shown in Fig. 2, $a$ and Fig. 3, $a$, respectively.

Heating the adsorbed $\mathrm{SF}_{6}$ layer results in a transformation of the ESDIAD patterns for both $\mathrm{F}^{+}$and $\mathrm{F}^{-}$ ions. As the temperature approaches $\sim 90 \mathrm{~K}$, the initial «halos» are replaced by distinct six-fold symmetry $a$

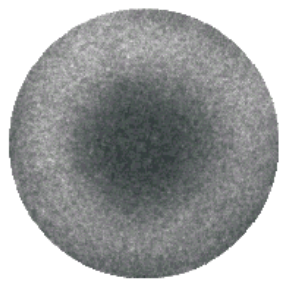

C

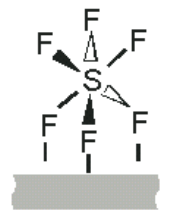

\section{$b$}

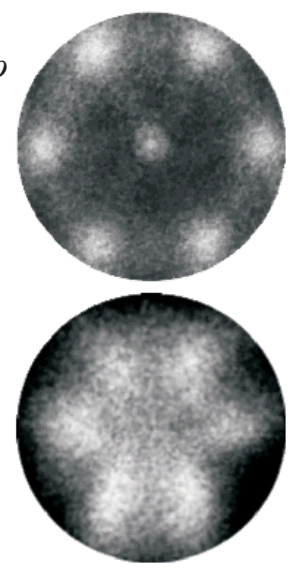

Fig. 2. ESDIAD patterns for $\mathrm{F}^{+}$and $\mathrm{F}^{-}$ions from 0.25 ML of $\mathrm{SF}_{6}$ on $\mathrm{Ru}(0001) . \mathrm{F}^{+}$ion halo-like pattern after deposition at $25 \mathrm{~K}(a)$. Heating the sample to $\sim 90 \mathrm{~K}$ results in hexagonal patterns for both $\mathrm{F}^{+}(b)$ and $\mathrm{F}^{-}(d)$ ions. The dynamics observed are consistent with adsorption of the molecule on $\mathrm{Ru}$ by 3 fluorine atoms $(c)$. Incident electron energy $E_{e}$ is $350 \mathrm{eV}$ for $\mathrm{F}^{+}$ion patterns and $250 \mathrm{eV}$ for $\mathrm{F}^{-}$ion pattern.

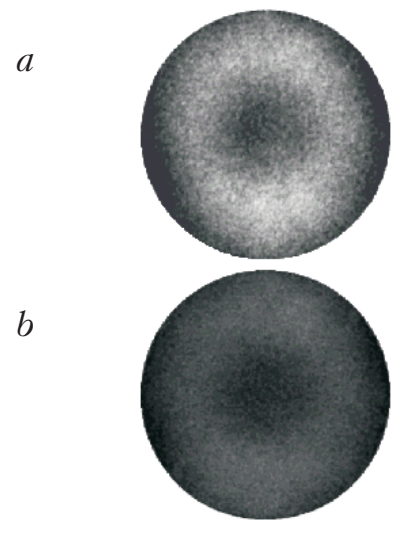

$c$

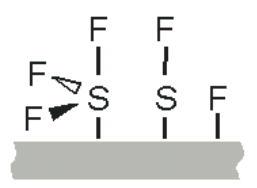

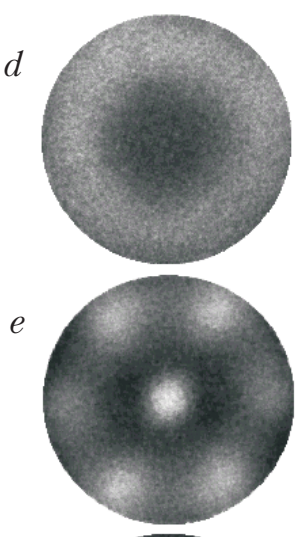

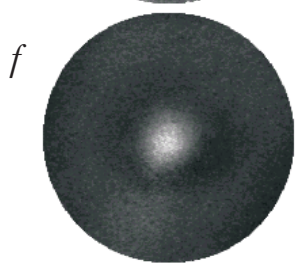

Fig. 3. ESDIAD patterns for $\mathrm{F}^{+}$and $\mathrm{F}^{-}$ions illustrating effects of electron irradiation on adsorbed $\mathrm{SF}_{6}$ : $\mathrm{F}^{-}$ions after deposition of $0.25 \mathrm{ML}$ of $\mathrm{SF}_{6}$ on $\mathrm{Ru}$ at $25 \mathrm{~K}(a) ; \mathrm{F}^{-}$ ions after electron exposure of $10^{15} \mathrm{~cm}^{-2}(b)$; possible sources of $\mathrm{F}^{+}$ion emission along surface normal $(c), \mathrm{F}^{+}$ ions after deposition of $0.25 \mathrm{ML}$ of $\mathrm{SF}_{6}(d) ; \mathrm{F}^{+}$ions after electron exposure of $10^{15} \mathrm{~cm}^{-2}(e) ; \mathrm{F}^{+}$ions after electron exposure of $10^{16} \mathrm{~cm}^{-2}(f)$. The patterns $(d-f)$ are measured for $350 \mathrm{eV}$ primary electrons; images $(a, b)$ are detected for $250 \mathrm{eV}$ electrons.

patterns for both ions $\left(\mathrm{F}^{+}\right.$: Fig. $2, b$ and $\mathrm{F}^{-}$: Fig. $\left.2, d\right)$. This temperature corresponds to the maximum rate of desorption of molecules from the first adsorbed layer [5].

Deposition of $\mathrm{SF}_{6}$ coverages higher than $0.33 \mathrm{ML}$ (saturation coverage) leads to changes in the angular distributions for both ions. The patterns become quite broad and featureless, with intensity centered on the surface normal, representing a random spatial orientation of molecules in the successive adsorbed molecular layers.

The «halo» patterns in Fig. 2, $a$ and Fig. 3, $a$ indicate a random azimuthal orientation of $\mathrm{SF}_{6}$ molecules adsorbed on $\mathrm{Ru}(0001)$ by 3 fluorine atoms with the other 3 pointing away (Fig. 2,c) [5,9]; no $\mathrm{S}-\mathrm{F}$ bonds are oriented along the surface normal. Heating the sample induces a rearrangement and ordering of the molecules, which results in the hexagonal patterns seen in Fig. 2,b and Fig. 2, $d$. The existence of six beams in Fig. 2, $b$ and Fig. 2, $d$ is attributed to the adsorption of $\mathrm{SF}_{6}$ in two azimuthally-oriented domains on $\mathrm{Ru}(0001)$, rotated by $60^{\circ}$ with respect to each other [5]. 


\subsection{Electron beam-induced changes in adsorbed $\mathrm{SF}_{6}$}

3.3.1. ESDIAD patterns. Typical transformations of the $\mathrm{F}^{-}$ESDIAD patterns observed under electron bombardment of $0.25 \mathrm{ML}$ of $\mathrm{SF}_{6}$ are illustrated in Fig. 3,a,b. Dynamics of the angular distribution of the $\mathrm{F}^{-}$ions are as follows: during electron bombardment the initial «halo» pattern (Fig. 3,a) loses its contrast very quickly (Fig. $3, b$ ) and then virtually disappears for electron exposures $>10^{15} \mathrm{~cm}^{-2}$. Thus, increasing electron exposure leads to a decrease of the total yield of $\mathrm{F}^{-}$ions, but does not induce a change in the angular distribution («halo» pattern) of this fragment; only heating of the surface causes the $\mathrm{F}^{-}$ESDIAD pattern to change from a «halo» to a hexagon.

In contrast to $\mathrm{F}^{-}$ions, the angular distributions for $\mathrm{F}^{+}$ions change under electron bombardment. Figure 3, $e$ shows that exposure of $0.25 \mathrm{ML}$ of adsorbed $\mathrm{SF}_{6}$ molecules to $\sim 10^{15} \mathrm{~cm}^{-2}$ results in the transformation of the initial «halo» (Fig. 3,d) into six off-normal beams and a prominent central peak. The angular positions of these beams are similar to those observed after heating (Fig. 2,b). The most noticeable difference between the hexagonal $\mathrm{F}^{+}$patterns in Fig. $2, b$ and Fig. 3,e is in the width of the beams. Further electron bombardment $\left(\sim 10^{16} \mathrm{~cm}^{-2}\right)$ results in the disappearance of the off-normal beams, and the gradual growth and saturation of the central peak (Fig. 3,f).

The observed changes in the ESDIAD patterns lead us to believe that $\mathrm{F}^{-}$ions originate primarily from undissociated molecularly adsorbed $\mathrm{SF}_{6}$, while the $\mathrm{F}^{+}$ ions originate from $\mathrm{SF}_{x}$ dissociation fragments.

3.3.2. Correlation between $\mathrm{F}^{+}$and $\mathrm{F}^{-}$ion desorption. The behavior of $\mathrm{F}^{+}$and $\mathrm{F}^{-}$ion desorption along normal and off-normal directions as a function of electron exposure is illustrated in Fig. 4. Each data point represents the integrated signal intensity for the indicated region of the ESDIAD patterns. For clarity, the data corresponding to the off-normal desorption of $\mathrm{F}^{+}$ions are divided by a factor of 6 .

There is evidence for correlated behavior of the curves in Fig. 4. Each data set demonstrates two distinct regions: the ion signals change rapidly for electron beam exposures $\leq 2 \cdot 10^{14} \mathrm{~cm}^{-2}$ and change more slowly for exposures $\geq 2 \cdot 10^{14} \mathrm{~cm}^{-2}$. (An exposure of $\sim 2 \cdot 10^{14} \mathrm{~cm}^{-2}$ corresponds approximately to one incident electron per two surface molecules.) In the initial region (at lower exposures), we observe an increase of the $\mathrm{F}^{+}$ion yield in the off-normal direction, and the appearance of the $\mathrm{F}^{+}$signal along the surface normal direction. Under the same conditions, the desorption signal for $\mathrm{F}^{-}$ions in the off-normal direction decreases very rapidly. The rate of the $\mathrm{F}^{-}$ion drop decreases at

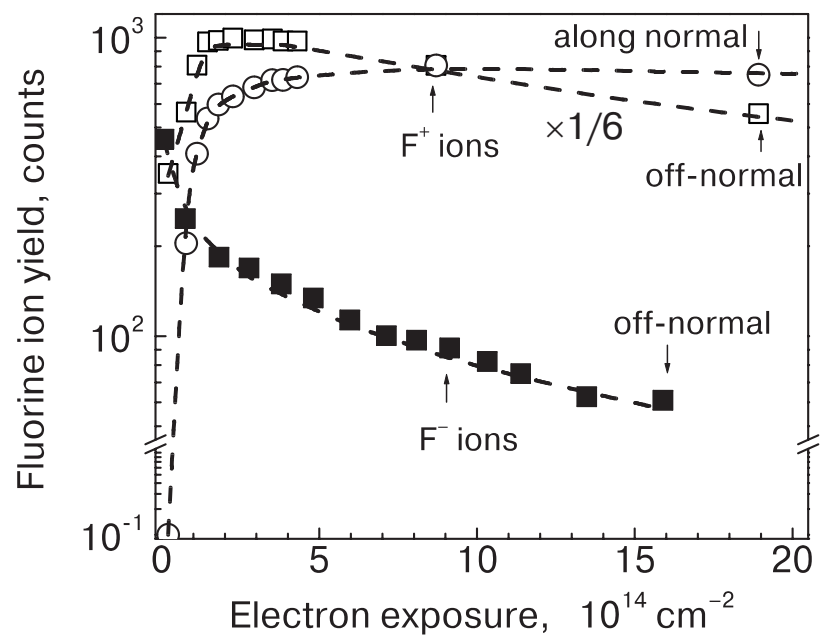

Fig. 4. Emission of fluorine ions from $0.25 \mathrm{ML}$ of $\mathrm{SF}_{6}$ in two directions: along the surface normal, and off the surface normal (hexagonal beams), as a function of electron exposure. The data are derived from ESDIAD patterns (cf. Fig. 3). Incident electron energy is $350 \mathrm{eV}$ for $\mathrm{F}^{+}$ions and $250 \mathrm{eV}$ for $\mathrm{F}^{-}$ions.

higher exposures, where the $\mathrm{F}^{+}$ion yield also changes: in the off-normal direction, the curve goes through a maximum and then exhibits exponential decay. Along the surface normal, the $\mathrm{F}^{+}$yield saturates and appears to decrease very slowly.

Thus, during electron beam exposures we observe a different ESD yield of $\mathrm{F}^{-}$and $\mathrm{F}^{+}$ions in off-normal directions $(a)$ and $\mathrm{F}^{+}$ions along the surface normal and off-normal directions $(b)$. This implies that $\mathrm{F}^{+}$and $\mathrm{F}^{-}$ ions are escaping from different species.

3.3.3. Influence of electron irradiation on $T P D$ spectra. In order to gain further insight into the dissociation process of $\mathrm{SF}_{6}$ on $\mathrm{Ru}(0001)$, we have also studied the influence of electron irradiation on TPD spectra. Electron beam exposure leads to a faster decrease of molecular $\mathrm{SF}_{6}$ in the first adsorbed layer as compared to that in the succeeding multilayers. As illustrated in Fig. 5, irradiation also results in a change of the shape of the monolayer feature, as well as a shift of the maximum desorption rate to higher temperatures. Exposure of $0.25 \mathrm{ML}$ of $\mathrm{SF}_{6}$ to $\sim 10^{16} \mathrm{~cm}^{-2}$ leads to an almost complete disappearance of adsorbed molecular $\mathrm{SF}_{6}$ on the surface. An even more surprising result is that the transformation of the fractional monolayer just described also occurs in the presence of succeeding adsorbed layers of $\mathrm{SF}_{6}$, which are not affected as strongly by electron beam irradiation (data not shown). In contrast, electron irradiation appears to affect only the amplitude of the multilayer peak in the TPD spectrum, while preserving the peak shape and position. 


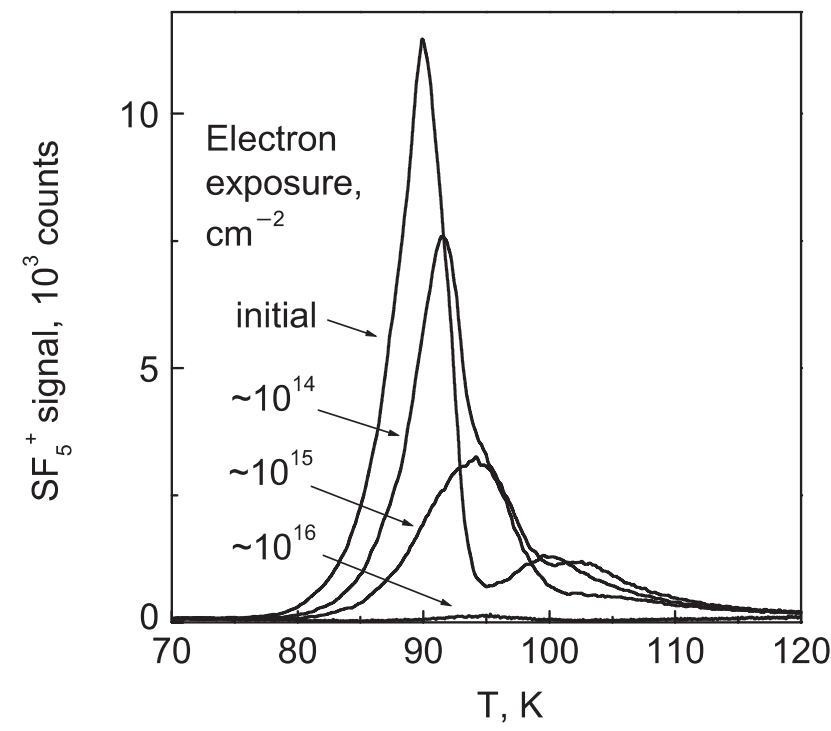

Fig. 5. Evolution of TPD spectra caused by electron irradiation of $0.25 \mathrm{ML}$ of $\mathrm{SF}_{6}$ on $\mathrm{Ru}$ at $25 \mathrm{~K}$. The electron source is the QMS filament, $E_{e}=90 \mathrm{eV}$.

Thus, it appears that molecules in contact with the $\mathrm{Ru}$ surface are more sensitive to dissociation than the molecules from upper adsorbed layers, which are isolated from the metal substrate.

\section{Discussion}

\subsection{Structure and bonding of $\mathrm{SF}_{6}$; thermal effects}

The primary issues that we address are the processes that take place in fractional monolayers of $\mathrm{SF}_{6}$ adsorbed on $\mathrm{Ru}(0001)$ upon electron bombardment. As already mentioned in the introduction, a number of studies of the adsorption and ion emission properties of $\mathrm{SF}_{6}$ adsorbed on various surfaces have been reported [7-10,21-26]. However, a gap in the understanding of the results still exists.

Our data indicate that $\mathrm{SF}_{6}$ molecules dosed onto $\mathrm{Ru}(0001)$ at $25 \mathrm{~K}$ are primarily physisorbed, based upon our TPD and ESDIAD results, and previous studies of adsorption of $\mathrm{SF}_{6}$ on $\mathrm{Ru}(0001)$ [9]. Physisorption is indicated by the closeness of the temperature at which the maximum rate of desorption of fractional monolayers of $\mathrm{SF}_{6}$ occurs $(\sim 90 \mathrm{~K})$ and the desorption temperature of condensed $\mathrm{SF}_{6}(\sim 80 \mathrm{~K})$. Physisorption of molecular $\mathrm{SF}_{6}$ has also been established on $\mathrm{Ni}(111)$ [22] and graphite (HOPG) [8].

The «halo» patterns in Fig. 2, $a$ and Fig. 3, $a$ indicate a random azimuthal orientation of $\mathrm{SF}_{6}$ molecules adsorbed on $\mathrm{Ru}(0001)$ by 3 fluorine atoms with the other 3 pointing away $[5,9]$. The «halo» pattern represents all the possible azimuthal orientations of $\mathrm{S}-\mathrm{F}$ bonds, since ESDIAD provides us with information averaged over a surface area determined by the electron beam size $\left(\sim 1 \mathrm{~mm}^{2}\right)$.

Heating to desorption temperatures $(\leq 90 \mathrm{~K})$ leads to a redistribution of the $\mathrm{F}^{-}$ion intensity from an initial «halo» to a hexagon [5]. Integration of ESDIAD patterns for $\mathrm{F}^{-}$ions (Fig. 2) reveals that the total ion intensity is essentially unchanged; upon redistribution of the intensity prior to the onset of desorption (from «halo» to hexagon) the integral signal remains nearly constant. As the $\mathrm{SF}_{6}$ desorbs thermally, the $\mathrm{F}^{-}$signals decrease.

The behavior of $\mathrm{F}^{+}$ions during heating to desorption temperatures $(\leq 90 \mathrm{~K})$ is virtually identical to that of $\mathrm{F}^{-}$ions. The initial «halo» pattern transforms into a hexagon and the total $\mathrm{F}^{+}$ion intensity remains constant. The $\mathrm{F}^{+}$ion hexagon differs slightly from the $\mathrm{F}^{-}$hexagon, in that a central beam is observed.

Both $\mathrm{F}^{+}$and $\mathrm{F}^{-}$ions are believed to escape from undissociated $\mathrm{SF}_{6}$ molecules, which have two preferential azimuthal orientations (giving six ion beams, rather than 3 beams expected for a single molecular orientation). The central beam in Fig. 2,b is due to ESD from a thermal decomposition product of $\mathrm{SF}_{6}$, either chemisorbed $\mathrm{F}$ or another fragment with an $\mathrm{S}-\mathrm{F}$ bond perpendicular to the surface. Dissociation of a small fraction of $\mathrm{SF}_{6}$ is supported by the persistence of an $\mathrm{F}^{+}$signal at temperatures $>120 \mathrm{~K}$, when desorption of the molecular $\mathrm{SF}_{6}$ is complete.

We attribute the temperature-induced changes of the ESDIAD patterns to the rearrangement of undissociated $\mathrm{SF}_{6}$ molecules, as they move to occupy energetically preferential adsorption sites. The rearrangement of the patterns for both $\mathrm{F}^{+}$and $\mathrm{F}^{-}$ions from initial «halos» to hexagons indicates ordering of the first adsorbed layer.

The orientation of $\mathrm{SF}_{6}$ molecules after heating to $\sim 90 \mathrm{~K}$ on $\mathrm{Ru}(0001)$ is established by comparison of ESDIAD patterns (Fig. 2,b and Fig. 2, $d$ ) and LEED images for the clean substrate. We identity the axis defined by the $\mathrm{S}-\mathrm{F}$ bond in the $\mathrm{SF}_{6}$ molecule to coincide with the $<10 \overline{1} 0>$ direction of ruthenium. Detailed analysis of adsorption properties and surface geometry of $\mathrm{SF}_{6}$ on $\mathrm{Ru}(0001)$ are reported elsewhere [5]. In this paper we focus primarily on electron beam-induced changes in the adsorbed layer.

\subsection{Electron beam-induced changes in adsorbed $\mathrm{SF}_{6}$}

4.2.1. ESDIAD patterns. Electron bombardment causes significant changes in $\mathrm{F}^{+}$and $\mathrm{F}^{-}$ESDIAD patterns. For exposures $\geq 10^{14} \mathrm{~cm}^{-2}$, the «halo» pattern due to $\mathrm{F}^{-}$ions (Fig. 3,a) loses its contrast very quickly and then virtually disappears (Fig. $3, b$ ). The 
initial «halo» pattern does not rearrange into a hexagon under electron irradiation. Electron bombardment leads to a decrease in the total ion yield, but the angular distribution of the $\mathrm{F}^{-}$ions remains the same. This observation leads to the suggestion that $\mathrm{F}^{-}$ions originate primarily from molecularly adsorbed $\mathrm{SF}_{6}$.

In contrast to the $\mathrm{F}^{-}$data, the angular distributions for $\mathrm{F}^{+}$ions $d o$ undergo significant changes under electron irradiation. As already mentioned, for exposures of $\sim 10^{15} \mathrm{~cm}^{-2}$, the initial «halo» pattern (Fig. 3,d) transforms into six off-normal beams in the shape of a hexagon and a prominent central beam (Fig. 3,e), very similar to the transformation that we observe upon heating to $>90 \mathrm{~K}$ (Fig. 2,b). More precisely, azimuthal angles for thermal- and electron beam-induced hexagon patterns are identical, and polar angles are very similar. More extensive irradiation $\left(10^{16} \mathrm{~cm}^{-2}\right)$ however, results in the disappearance of the off-normal beams and growth and saturation of the central beam (Fig. 3,f). In contrast to the $\mathrm{F}^{-}$intensity, the $\mathrm{F}^{+}$ ion intensity increases with increasing electron exposure. These behaviors suggest that $\mathrm{F}^{+}$ions originate also from $\mathrm{SF}_{x}$ dissociation fragments.

4.2.2. Ordering of dissociation fragments. The similarity of the transformation of the $\mathrm{F}^{+}$ESDIAD patterns from a «halo» to a hexagon upon both heating and electron exposure, makes it tempting to suggest that electron beam exposure of disordered $\mathrm{SF}_{6}$ molecules ( «halo» pattern) leads to electron-induced ordering (hexagon pattern), similar to thermally induced ordering. Electron-stimulated mobility of adsorbed species at low temperatures is well known $[27,28]$. However, the differences between $\mathrm{F}^{+}$and $\mathrm{F}^{-}$ ESDIAD patterns during electron irradiation strongly suggest that electron bombardment causes dissociation of the adsorbed molecular $\mathrm{SF}_{6}$, rather than ordering of the adsorbed layer, and that $\mathrm{F}^{-}$ions escape from undissociated $\mathrm{SF}_{6}$ molecules. This is supported by the observation that the $\mathrm{F}^{-}$«halo» (Fig. 3, $a, b$ ) simply disappears as electron exposure increases. This is a consequence of the dissociation of $\mathrm{SF}_{6}$ under electron bombardment: upon dissociation of $\mathrm{SF}_{6}$, the $\mathrm{F}^{-}$signal is reduced, while new features in $\mathrm{F}^{+}$ESDIAD patterns emerge.

4.2.3. Origins of $\mathrm{F}^{-}, \mathrm{F}^{+}$ions; nature of molecular fragments. In the following paragraphs, we discuss the nature of the molecular species and fragments that contribute to the observed $\mathrm{F}^{+}$and $\mathrm{F}^{-}$ESDIAD patterns. As previously mentioned, the excitations leading to $\mathrm{F}^{-}$and $\mathrm{F}^{+}$ions are very different: $\mathrm{F}^{-}$is a product of DEA excited by low-energy secondary electrons from the substrate,

$$
e^{-}+\mathrm{SF}_{6} \rightarrow\left(\mathrm{SF}_{6}^{*}\right)^{-} \rightarrow \mathrm{SF}_{5}+\mathrm{F}^{-}
$$

with two resonant features at electron energies of $5.8 \mathrm{eV}$ and $\sim 11 \mathrm{eV}$ for the condensed phase; dipolar dissociation also contributes at higher energies.

In contrast, $\mathrm{F}^{+}$ions are due to core excitations (probably F $2 s$ )

$$
e^{-}+\mathrm{SF}_{6} \rightarrow\left(\mathrm{SF}_{6}{ }^{*}\right)^{+} \rightarrow \mathrm{SF}_{5}^{+}+\mathrm{F}^{+}+2 e^{-}
$$

with a threshold energy of $\sim 30 \mathrm{eV}$.

Our TPD spectra (Fig. 5) support the proposal that $\mathrm{F}^{-}$ions originate from undissociated $\mathrm{SF}_{6}$. The area under a TPD curve is known to be proportional to the number of molecules desorbed thermally and, in our case, undissociated $\mathrm{SF}_{6}$ and $/$ or $\mathrm{SF}_{6}$ that forms by recombination upon heating the surface. Damage kinetics of $\mathrm{SF}_{6}$ due to electron bombardment (derived from TPD measurements, Fig. 5) and the dependence of the $\mathrm{F}^{-}$ion yield on electron exposure (derived from ESDIAD signals) are compared in Fig. 6. The data are normalized for clarity and presented in relative units. The drop in $\mathrm{F}^{-}$ion yield is correlated with the decay of the concentration of undissociated $\mathrm{SF}_{6}$ molecules on the surface. The quantitative differences in the two data sets of Fig. 6 are attributed to errors in determining electron beam exposure in the two experiments (focused beam for ESDIAD vs defocused electron source for TPD), and to the difference in incident electron energy $(90 \mathrm{eV}$ for TPD, $250 \mathrm{eV}$ for ESDIAD).

The change in the angular distribution of the $\mathrm{F}^{+}$ ions indicates that after electron irradiation, the $\mathrm{F}^{+}$ ions do not escape from undissociated molecular $\mathrm{SF}_{6}$, but rather from dissociation fragments $\mathrm{SF}_{x}$. Recently

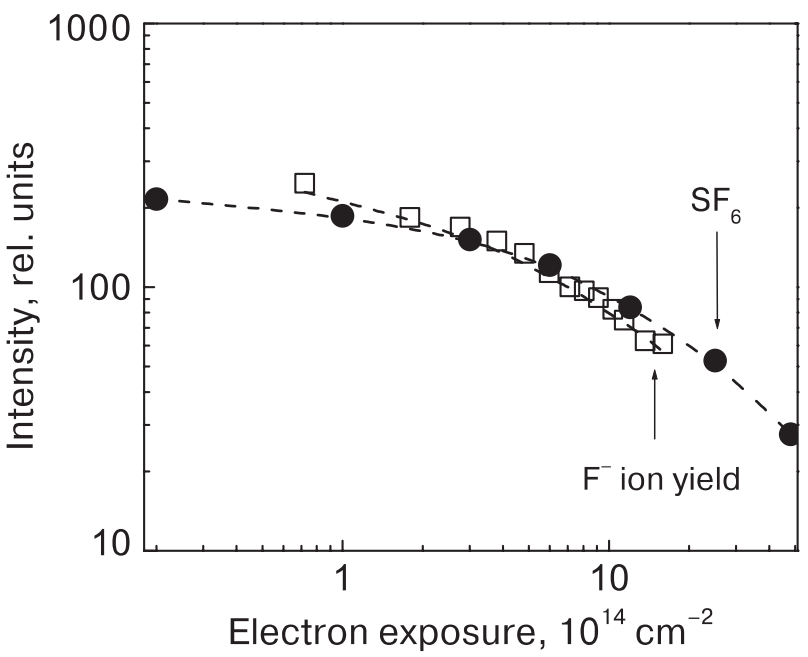

Fig. 6. A comparison of negative fluorine ion yields (derived from ESDIAD patterns, e.g., Fig. 3 and plotted in Fig. 4; $E_{e}=250 \mathrm{eV}$ ) and relative concentration of undissociated $\mathrm{SF}_{6}$ molecules (derived from TPD spectra, Fig. 5; $E_{e}=90 \mathrm{eV}$ ) as a function of electron exposure. The data are measured for $0.25 \mathrm{ML}$ of $\mathrm{SF}_{6}$ on $\mathrm{Ru}$. 
Souda [25], in a study of secondary-ion emission from $\mathrm{SF}_{6}$ adsorbed on Pt(111) observed an increase of one order of magnitude in the yield of $\mathrm{F}^{+}$ions after electron irradiation. He suggested that the $\mathrm{F}^{+}$ions arise from chemisorbed $\mathrm{F}$ adatoms or dissociation fragments $\left(\mathrm{SF}_{x}\right)$. This observation is in agreement with the increase in $\mathrm{F}^{+}$ion yields upon electron exposures shown in Fig. 4. (See Sect. 4.2 for discussion of Fig. 4). The angular resolution of our ESDIAD images allows us to distinguish between ions that escape normal to the surface, i.e., from $\mathrm{SF}_{x}$ species with an $\mathrm{S}-\mathrm{F}$ bond perpendicular to the surface or fluorine atoms bound directly to the surface (Fig. 3,c), and those that escape from $\mathrm{SF}_{x}(x=2-5)$ with $\mathrm{S}-\mathrm{F}$ bonds directed in off-normal directions.

The hexagon (Fig. 3, $e$ ) that is clearly seen after exposures of $\sim 10^{15} \mathrm{~cm}^{-2}$ is formed by $\mathrm{F}^{+}$ions from dissociation fragments $\left(\mathrm{SF}_{x}\right)$, which desorb from the surface along an off-normal direction. The $\mathrm{F}^{+}$beams observed in the pattern after irradiation (Fig. 3,e) look broader and more asymmetric than the beams of the hexagon detected after heating (Fig. 2,b), suggesting that several $\mathrm{SF}_{x}$ species with $\mathrm{S}-\mathrm{F}$ bonds in off normal directions could be contributing to the six $\mathrm{F}^{+}$beams. It is most interesting that these fragments tend to be ordered on the surface (we observe a hexagon instead of a «halo»), in a manner very similar to the results obtained during irradiation-induced decomposition of $\mathrm{PF}_{3}$ molecules adsorbed on $\mathrm{Ru}(0001)$ $[27,28]$. Based upon theoretical equilibrium structures of $\mathrm{SF}_{x}(x=1-6)$ [29] and simple bonding symmetry considerations similar to those for domains of $\mathrm{PF}_{2}$ [12], it is possible that the hexagon originates, for example, from 3 domains of $\mathrm{SF}_{4}$ species, or bridge-bonded $\mathrm{SF}_{2}$ species, azimuthally rotated by $120^{\circ}$ as shown in Fig. 7. Other fragments, including inclined SF, could also contribute to the off-normal $\mathrm{F}^{+}$ion yields.

The central beam, caused by $\mathrm{F}^{+}$ions desorbing normal to the surface, most probably contains contributions from chemisorbed $\mathrm{F}$ adatoms. However, fragments such as $\mathrm{SF}, \mathrm{SF}_{3}$ and $\mathrm{SF}_{5}$ might also contribute to the central beam [29].

At present the identity of the dissociation fragments is an open issue, as we lack direct knowledge about the stoichiometry and the structure of $\mathrm{SF}_{x}$ fragments adsorbed on the Ru substrate. Additional experiments (e.g. high resolution soft x-ray photoemission spectroscopy [30]) and theoretical guidance are needed to resolve these issues.

Figure 4 is a plot of ESDIAD intensity as a function of electron exposure. Both the «along normal» and «off-normal» $\mathrm{F}^{+}$curves grow rapidly at low electron exposures. The rapid initial rise is probably due $a$
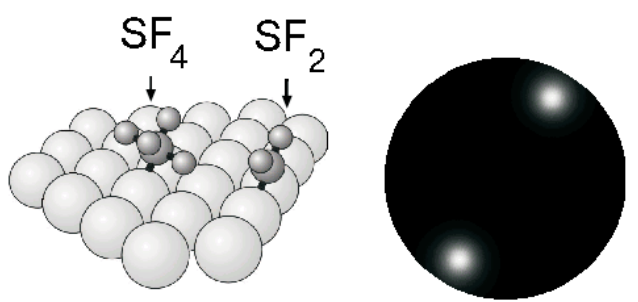

$b$ $\mathrm{SF}_{2}$
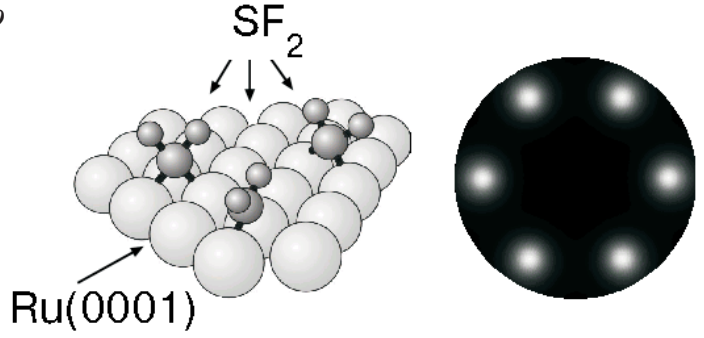

Fig. 7. Schematic representation of bridge-bonded $\mathrm{SF}_{2}$ and $\mathrm{SF}_{4}$ species on ruthenium surface (on the left) and corresponding simulated ESDIAD pattern (on the right) (a); illustrates formation of hexagonal ESDIAD pattern (simulated image is on the right) from 3 domains of $\mathrm{SF}_{2}$ species, azimuthally rotated by $120^{\circ}$ (shown on the left) (b).

to very efficient dissociation in the initial stages of the decomposition of molecular $\mathrm{SF}_{6}$. In the initial stages (at low electron exposures) there are many adsorption sites available for the dissociation fragments of $\mathrm{SF}_{6}$ on the $\mathrm{Ru}(0001)$ surface. Being in contact with the metal surface enhances the reactivity of fragments and makes them more prone to dissociate. As the dissociation process continues at higher electron exposures, the $\mathrm{Ru}(0001)$ surface becomes «filled», and the rate of further dissociation is greatly reduced. This suggests that low coverages of $\mathrm{SF}_{6}$ have a higher dissociation rate than higher coverages.

In concluding this part of the discussion, we note that there is previous evidence from ESD studies of $\mathrm{PF}_{3}$ and $\left(\mathrm{CF}_{3}\right)_{2} \mathrm{CO}$ to support the contention that negative ion desorption arises mainly from molecularly-intact adsorbates, while positive ion desorption can be dominated also by dissociative fragments, when they are present [27]. We suggest that the temporary-negative-ion states formed during DEA of molecules such as $\mathrm{SF}_{6}$, etc., are more weakly coupled to the surface than similar states associated with more strongly chemisorbed fragments. Thus, the lifetime for DEA of intact molecules is expected to be longer than for possible DEA of chemisorbed dissociation fragments, making the probability of $\mathrm{F}^{-}$desorption from molecules higher than from fragments.

4.2.4. Estimation of cross-sections for desorption and dissociation. In the discussion of the origin of the 
$\mathrm{F}^{-}$ion, we made reference to Fig. 6, which clearly shows a correlation between the drop in $\mathrm{F}^{-}$ion yield with a decrease in the number of undissociated $\mathrm{SF}_{6}$ molecules left on the surface after irradiation. As described elsewhere [31], exposure-dependent surface coverage $\theta$ can be roughly expressed by the exponential law:

$$
\theta=\theta_{0} \exp \left(-\sigma_{\text {esd }} F_{e}\right),
$$

where $\sigma_{\text {esd }}$ is the total cross-section $\left(\mathrm{cm}^{2}\right)$ of molecular $\mathrm{SF}_{6}$ for electron-stimulated desorption and/or dissociation and $F_{e}$ is electron exposure $\left(\mathrm{cm}^{-2}\right)$.

Recent measurements [20] indicate that the $\mathrm{F}^{-}$signal is directly proportional to $\theta_{\mathrm{SF} 6}$, and we approximate the total cross-section for electron induced dissociation of a fractional monolayer ( $0.25 \mathrm{ML})$ of $\mathrm{SF}_{6}$ on $\mathrm{Ru}(0001)$ from the $\mathrm{F}^{-}$intensity curve in Fig. 4. We find that for $250 \mathrm{eV}$ incident electron energy, $\sigma_{\text {esd }}$ is $\sim(6 \pm 2) \cdot 10^{-15} \mathrm{~cm}^{2}$ for electron exposures $<2 \cdot 10^{14} \mathrm{~cm}^{-2}$ and $\sim(8 \pm 2) \cdot 10^{-16} \mathrm{~cm}^{2}$ for electron exposures $>2 \cdot 10^{-14} \mathrm{~cm}^{-2}$, an order of magnitude difference. A qualitatively similar result has been derived from damage kinetics of molecular $\mathrm{SF}_{6}$ shown in Fig. 6 (primary electron energy $\sim 90 \mathrm{eV}): \sim(2 \pm$ $\pm 1) \cdot 10^{-15} \mathrm{~cm}^{2}$ for exposures $<2 \cdot 10^{14} \mathrm{~cm}^{-2}$ and $\sim(4 \pm$ $\pm 1) \cdot 10^{-16} \mathrm{~cm}^{2}$ for higher electron exposures. As already indicated in the previous section, $\sigma_{\text {esd }}$ is expected to be greater at initial electron exposures, since there are many adsorption sites available to the dissociation fragments, allowing them to interact with the $\mathrm{Ru}$ substrate and increase their reactivity.

Our rough calculations of $\sigma_{\text {esd }}$ indicate that the total dissociation/desorption cross section for fractional $\mathrm{SF}_{6}$ adsorbed on $\mathrm{Ru}$ for low electron exposures is about 1 order of magnitude greater than for gaseous $\mathrm{SF}_{6}$. In the case of DEA it has been shown that the cross-section is often greater for molecules condensed on a substrate than for the gas-phase analogue. The increase is explained in terms of the induced polarization energy due to the substrate, which stabilizes a negative ion against autodetachment [32].

In our experiments there are two sources of electrons, primary and secondary, that can cause dissociation: 1) energetic primary electrons can initiate dissociative ionization and/or dipolar dissociation and 2) low-energy secondary electrons (originating from the $\mathrm{Ru}$ substrate) can lead to DEA, and to a lesser extent, dissociative ionization. Secondary electrons have a maximum yield at $0-2 \mathrm{eV}$ with a high energy tail extending to $20-30 \mathrm{eV}$.

There have been several measurements of electron impact ionization cross-sections for gaseous $\mathrm{SF}_{6}$. Dissociative ionization (which results in the formation of positive ions) of gaseous $\mathrm{SF}_{6}$ becomes significant for electron energies $>16 \mathrm{eV}$, and exhibits a maximum cross-section of $\sim 7 \cdot 10^{-16} \mathrm{~cm}^{2}$ for electron energies of $\sim 100 \mathrm{eV}[6]$.

DEA (which results in the formation of neutral fragments and negative ions) is appreciable only for low energy electrons, $0-15 \mathrm{eV}$. The maximum cross-section of $2 \cdot 10^{-16} \mathrm{~cm}^{2}$ occurs for electron energies of $\sim 0.1-0.5 \mathrm{eV}$, and is due mainly to the formation of $\mathrm{SF}_{5}^{-}$[6].

The different behavior of the monolayer and multilayer features in TPD spectra during electron irradiation (see explanation of Fig. 5 in previous section), leads us to believe that the average cross-section for electron-induced dissociation of $\mathrm{SF}_{6}$ fractional monolayer coverages is approximately one order of magnitude greater than for multilayers. The higher rate of dissociation of $\mathrm{SF}_{6}$ molecules in contact with the $\mathrm{Ru}(0001)$ surface provides indirect evidence of the important contribution of DEA to the total dissociation process of $\mathrm{SF}_{6}$ on $\mathrm{Ru}(0001)$. Low-energy secondary electrons are known to play a major role in DEA [3], which is an extremely efficient process in collisions of low-energy electrons with gas- and condensed-phase halogenated molecules. In addition, an electronically excited species in contact with the metal tends to react more easily than when it is isolated from the metal.

\subsection{ESD mass-spectra}

The interaction of adsorbed $\mathrm{SF}_{6}$ molecules with the $\mathrm{Ru}(0001)$ substrate is responsible for the substantial differences in the ESD mass-spectra (Fig. 1) between fractional monolayer and multilayer coverages. As mentioned in the description of Fig. 1, the ESD mass-spectra for fractional monolayer coverages exhibits only a strong $\mathrm{F}^{+}$ion signal; the yield of other fragments is suppressed. However, the spectrum for $2.5 \mathrm{ML}$ of $\mathrm{SF}_{6}$ displays a variety of desorbing species. A very similar effect was observed for the adsorption of $\mathrm{C}_{6} \mathrm{H}_{12}$ on $\mathrm{Ru}(0001)$ : ESD of a $\mathrm{C}_{6} \mathrm{H}_{12}$ monolayer was observed to yield only $\mathrm{H}^{+}$, while multilayer coverages yielded many more ionic fragments [33]. It was suggested that for the monolayer species in direct contact with the substrate, the probability of electron-induced dissociation is high, but that de-excitation processes involving electron tunneling from the substrate also occur with high probability. This leads to suppression of desorption of slow-moving, massive ion fragments (see discussion of mass effects in ESD by Madey et al. [34]). Our ESD mass-spectra are consistent with these considerations: for fractional monolayer coverages we observe only a strong $\mathrm{F}^{+}$ yield, while multilayer coverages yield more ionic fragments. 


\section{Conclusion}

We have studied ESD of $\mathrm{F}^{+}$and $\mathrm{F}^{-}$ions from fractional monolayers of $\mathrm{SF}_{6}$ on $\mathrm{Ru}(0001)$ at $25 \mathrm{~K}$ as a function of electron irradiation. The origin of these ions appears to be strongly dependent on the electron exposure.

For exposures less than $\sim 10^{13} \mathrm{~cm}^{-2}$ both $\mathrm{F}^{+}$and $\mathrm{F}^{-}$ ions observed in off-normal directions arise from undissociated $\mathrm{SF}_{6}$ molecules. Higher electron exposures $\left(\geq 10^{14} \mathrm{~cm}^{-2}\right)$ lead to stepwise decomposition of the parent $\mathrm{SF}_{6}$ molecule, with the $\mathrm{F}^{+}$and $\mathrm{F}^{-}$ions escaping from different species: whereas the $\mathrm{F}^{-}$ion is still emitted by undissociated $\mathrm{SF}_{6}$ molecules, the $\mathrm{F}^{+}$ions escape in off-normal directions from $\mathrm{SF}_{x}(x=2-5)$ fragments. $\mathrm{SF}_{x}$ fragments are ordered on the surface, which is indicated by the observed hexagonal ESDIAD patterns for $\mathrm{F}^{+}$after irradiation. Along directions normal to the surface, the $\mathrm{F}^{+}$ions arise most likely from dissociation fragments with an $\mathrm{S}-\mathrm{F}$ bond normal to the surface, and chemically bonded $\mathrm{F}$ adatoms. Adsorbed $\mathrm{SF}_{6}$ molecules and $\mathrm{SF}_{x}$ fragments decompose almost completely after electron exposures of $\sim 10^{16} \mathrm{~cm}^{-2}$. The total cross section for electron-impact dissociation of molecular $\mathrm{SF}_{6}$ on $\mathrm{Ru}$ (incident electron energy $\sim 250 \mathrm{eV})$ is found to be $\sim(6 \pm$ $\pm 2) \cdot 10^{-15} \mathrm{~cm}^{2}$ for electron exposures $<2 \cdot 10^{14} \mathrm{~cm}^{-2}$ (which is about 1 order of magnitude greater than for gaseous $\left.\mathrm{SF}_{6}\right)$, and $\sim(8 \pm 2) \cdot 10^{-16} \mathrm{~cm}^{2}$ for higher electron exposures.

\section{Acknowledgments}

We acknowledge valuable discussions with Prof. E. Carter. This work has been supported in part by the US National Science Foundation, Grant No. CHE 0075995 .

1. Q.-B. Lu and T.E. Madey, Phys. Rev. Lett. 82, 4122 (1999).

2. Q.-B. Lu and T.E. Madey, Surf. Sci. 451, 238 (2000).

3. Q.-B. Lu and T.E. Madey, J. Phys. Chem. B105, 2779 (2001).

4. S.S. Solovev, D. Kusmierek, and T.E. Madey, in preparation.

5. N. S. Faradzhev, D.O. Kusmierek, B.V. Yakshinskiy, S.S. Solovev, and T.E. Madey, submitted to Surf. Sci.

6. L.G. Christophorou and J.K. Olthoff, J. Phys. Chem. Ref. Data 29, 267 (2000).

7. F. Weik, E. Illenberger, J. Chem. Phys. 109, 6079 (1998).

8. L. Siller, N. Vanter, and R.E. Palmer, Surf. Sci. 465, 76 (2000).

9. G.B. Fisher, N.E. Erickson, T.E. Madey, and J.T. Yates, Surf. Sci. 65, 210 (1977).
10. Klekamp, E. Umbach, Chem. Phys. Lett. 171, 233 (1990).

11. T.E. Madey, Science 234, 316 (1986).

12. T.E. Madey, H.S. Tao, L. Nair, U. Diebold, S.M. Shivaprasad, A.L. Johnson, A. Poradzisz, N.D. Shinn, J.A. Yarmoff, V. Chakarian, and D. Shuh, Desorption Induced by Electron Transitions DIET V (1993), p. 182.

13. T. Stanski and B. Adamczyk, Int. J. Mass. Spectrom. Ion Phys. 46, 31 (1983).

14. D. Margreiter, G. Walder, H. Deutsch, H.U. Poll, C. Winkler, K. Stephan, and T.D. Märk, Int. J. Mass. Spectrom. Ion Processes 100, 143 (1990).

15. Q.-B. Lu, Z. Ma, and T.E. Madey, Phys. Rev. B58, 16446 (1998).

16. M. Akbulut, T.E. Madey, L. Patenteau, and L. Sanche, J. Chem. Phys. 105, 6043 (1996).

17. Q.-B. Lu and T.E. Madey, J. Chem. Phys. 111, 2861 (1999).

18. IR and Mass Spectra, in: NIST Chemistry WebBook, NIST Standard Reference Database, Vol. 69, P.J. Linstrom and W.G. Mallard (eds.), National Institute of Standards and Technology, Gaithersburg MD (2001); (http://webbook.nist.gov).

19. N.J. Sack, M. Akbulut, T.E. Madey, P. Klein, H.M. Urbassek, and M. Vicanek, Phys. Rev. B54, 5130 (1996).

20. N. S. Faradzhev, D. O. Kusmierek, B. V. Yakshinskiy, and T.E. Madey, in preparation.

21. T.E. Madey and J.T. Yates, Surf. Sci. 63, 203 (1977).

22. A. Klekamp and E. Umbach, Surf. Sci. 249, 75 (1991).

23. A. Klekamp and E. Umbach, Surf. Sci. 271, 555 (1992).

24. A. Klekamp and E. Umbach, Surf. Sci. 284, 291 (1993).

25. R. Souda, J. Chem. Phys. 114, 1823 (2001); ibid. 114, 3293 (2001).

26. A.G. Fedorus, E.V. Klimenko, A.G. Naumovets, E.M. Zasimovich, and I.N. Zasimovich, Nucl. Instrum. Methods. in Phys. Res. B101, 207 (1995).

27. A.L. Johnson, S.A. Joyce, and T.E. Madey, Phys. Rev. Lett. 61, 2578 (1988).

28. S.A. Joyce, A.L. Johnson, and T.E. Madey, J. Vac. Sci. Technol. A7, 2221 (1989).

29. Y.-S. Cheung, Y.-J. Chen, C.Y. Ng, See-Wing Chiu, and Wai-Kee Li, J. Am. Chem. Soc. 117, 9725 (1995).

30. H.-S. Tao, U. Diebold, V. Chakarian, D.K. Schu, J.A. Yarmoff, N.D. Shinn, and T.E. Madey, J. Vac. Sci. Technol. A13(5), 2553 (1995).

31. T.E. Madey and J.T. Yates, J. Vac. Sci. Technol. 8, 525 (1971).

32. F. Weik, E. Illenberger, K. Nagesha, and L. Sanche, J. Phys. Chem. B102, 824 (1998).

33. T.E. Madey and J.T. Yates, Surf. Sci. 76, 397 (1978).

34. T.E. Madey, J.T. Yates, Jr., D.A. King, and C.J. Uhlaner, J. Chem. Phys. 52, 5215 (1970). 